2 Keenan JS, Brassell EG. A study of factors related to prognosis for individual aphasic patients. J Speech Hear Disord 1974; 34:257-69.

3 Kertesz A. McCabe P. Recovery patterns and prognosis in aphasia. Brain 1977;100:1-18.

4 Sarno MT, Silverman M, Levita E. Psychosocial factors and recovery in geriatric patients with severe aphasia. $J \boldsymbol{A M}$ Geriat Soc 1970;18:405-9.

5 Sands E, Sarno MT, Shankweiler D. Long term assessment of language function in aphasia due to stroke. Arch Phys Med Rehab 1969;50:202-6.

6 Eslinger PJ, Damasio AR. Age and type of aphasia in patients with stroke. $J$ Neurol Neurosurg Psychiatry 1981;44:377-81.

7 Kertesz A, Sheppard A, Age and sex in aphasic stroke. Brain 1981;104:117-28.

8 Basso A, Capitani E, Vignolo LA. Influence of rehabilitation on language skills in aphasic patients: a controlled study. Arch Neurol 1979:36:190-6.

9 Sarno MT, Levita E. Recovery in treated aphasia in the first year post stroke. Stroke 1979:10:663-70.

10 David RM, Enderby P, Bainton D. Treatment of acquired aphasia: speech therapists and volunteers compared. J Neurol Neurosurg Psychiatry 1982:45:957-61.

11 Brust J, Shafer S, Richter R, Brunn B. Aphasia in acute stroke. Stroke 1976;7:167-74.

12 McGlone J, Kertesz A. Sex differences in cerebral processing of visuospatial tasks. Corlex 1973;9:313-20.

13 Sarno MT, Silverman M, Sands E. Speech therapy and language recovery in severe aphasia. J Speech Hear Res 1969;13:607-23.

14 Porch BE. The Porch Index of Communicative Ability. Palo Alto: The Consulting Psychologists Press, 1967.

15 Sarno MT. The Functional Communication Profile: Manual of Directions. Rehabilitation Monograph 42, New York: Institute of Rehabilitation Medicine, 1969.

16 Goodglass H, Kaplan E. The Assessment of Aphasia and Related Disorders. Boston: Lea and Febiger 1972.

17 Lendrem W, Lincoln NB. Spontaneous recovery of language abilities in stroke patients between 4 and 34 weeks after stroke. $J$ Neurol Neurosurg Psychiatry 1985;48: 743-8.

Accepted 2 April 1988

\section{Noradrenaline, adrenaline and tyrosine hydroxylase in adrenal medulla from Parkinsonian patients}

Sir: Recent experimental ${ }^{12}$ and clinical $^{34}$ studies have suggested that autografting tissue from adrenal medulla into the striatum may improve symptoms resulting from nigro-striatal dopamine degeneration. Parkinson's disease is associated with a severe dopaminergic and noradrenergic deficiency in the brain. ${ }^{5}$ Whether the disease affects central dopamine or noradrenaline levels, or peripheral levels as well, in particular those of the adrenal medulla, has not been reported and is of interest with regard to the usefulness of autografts in patients. ${ }^{34}$

Nine adrenal glands from subjects with no evidence of endocrinological, psychiatric or neurological disease (mean age: 75.3, SEM 1.9 years; post-mortem delay: 18.2 , SEM 2.9 hours (range: 6.5-30)) and 12 adrenal glands from patients with Parkinson's disease (mean age: 73.9, SEM 3 years; post-mortem delay: 20.6, SEM 1.7 hours (range 10-29)) were examined. The adrenal glands were stored at $-70^{\circ} \mathrm{C}$, until adrenal medulla was dissected free from the cortex at $-15^{\circ} \mathrm{C}$, under a dissecting microscope. The whole tissue from each adrenal medulla was crushed into powder on dry ice, and biochemical assays were performed on an aliquot of the structure. Noradrenaline, adrenaline and dopamine were assayed by high performance liquid chromatography with electrochemical detection. ${ }^{6}$ The dopamine values are not mentioned as they were too low (in the order of $1 \mathrm{ng}$ per $\mathrm{mg}$ tissue) and not reproducible. Tyrosine hydroxylase activity was assayed according to Puymirat et al. ${ }^{7}$

The catecholamine content in adrenals from control subjects was in good agreement with studies in monkey ${ }^{8}$ (table). Adrenaline concentrations were four times higher than those of noradrenaline. In adrenal glands from patients with Parkinson's disease, the levels of noradrenaline, adrenaline and tyrosine hydroxylase activity were slightly but not significantly decreased compared with control values (table). These observations contrast with the previously reported deficiency in tyrosinehydroxylase, ${ }^{9}$ and suggest that the catecholaminergic systems in the adrenal medulla (unlike those in the brain) ${ }^{5}$ are not markedly affected in the disease. Thus the histopathological changes observed in adrenals in cases of Parkinson's disease $^{10}$ may not be associated with a

Table Noradrenaline, adrenaline and tyrosine hydroxylase levels in adrenal medullas from Parkinsonian patients

\begin{tabular}{lll}
\hline & $\begin{array}{c}\text { Control } \\
(n=9)\end{array}$ & $\begin{array}{c}\text { Parkinson } \\
(n=12)\end{array}$ \\
\hline $\begin{array}{l}\text { Noradrenaline } \\
\text { Adrenaline }\end{array}$ & 194,43 & 167,45 \\
Tyrosine hydroxylase & 866,144 & 644,168 \\
\hline
\end{tabular}

Values are expressed in $\mathrm{ng} / \mathrm{mg}$ tissue for catecholamines and $\mathrm{pg} / \mathrm{h} / \mathrm{mg}$ tissue for tyrosine hydroxylase activity.

$\mathbf{n}=$ number of adrenal glands.

Data are the mean, SEM. massive catecholaminergic degeneration In monkey, the Parkinsonian syndromeinduced by the administratio of MPTP (1-methyl-4-phenyl-1,2,3,6-tetra hydropyridine) is not associated with की deficiency in adrenal gland catecholamine content $^{18}$ a difference from the centraf effects of the neurotoxin. Therefore, braips catecholaminergic neurons seem to have specific vulnerability. The present data: (1 emphasise that adrenal autografts in the stri atum of patients have the biochemicar. capacity to substitute a catecholaminergi activity; (2) suggest that the targets of the pathogenic process in Parkinson's diseas are mostly restricted to catecholaminergie neurons in the central nervous system; (3⿻ are compatible with an efficiency of adrenas medulla autografts in patients with $\mathrm{Par}_{\overline{0}}$ kinson's disease. The mechanism by whickp these autografts provide a clinica $\bar{b}$ improvement remains unknown: tyrosinehydroxylase might restore dopamine neuro $\vec{\omega}$ transmission; implanted cells may rein nervate the host striatum; grafted cellạ̧ might induce some recovery of dopamine neurons. ${ }^{111}$

$$
\begin{aligned}
& \text { P CERVERA } \\
& \text { O RASC虫 } \\
& \text { A PLOS牙 } \\
& \text { G GAILLARD } \\
& \text { R RAISM \& } \\
& \text { C DUYCKAERTS } \\
& \text { JJ HAUNW } \\
& \text { D SCHERM⿻ి } \\
& \text { JL MONTASTREC } \\
& \text { F JAVOY-A@再草 } \\
& \text { Y AG两㖞 }
\end{aligned}
$$

INSERM U 289, Nouvelle Pharmaciẹ Hôpital de la Salpêtrière,* 75013 PARISt INSERM U 317, Laboratoire de

Pharmacologie Mèdicale et Cliniqueș Faculté de Médecine, 31073 TOULOUSE.

Laboratoire Raymond Escourolle, Hôpitọ de la Salpêtrière, $\ddagger 75013$ PARISQ

CNRS UA 1112, Institut de Biologi Physico-chimique, 75005 PARIS,§ France

\section{References}

1 Bohn M, Cupit L, Marciano F, Gash DM Adrenal medulla grafts enhance recovery striatal dopaminergic fibers. Science 198 ţ 237:913-6.

2 Björklund A, Dunnett SB, Steveni U, Lewiss ME, Iversen SD. Reinnervation of the denervated striatum by substantia nigra transplants: functional consequences $2 \mathrm{~S}$ revealed by pharmacological and sensor? motor testing. Brain Res 1980;199:307-33

3 Backlund EO, Grandberg PO, Hamberger B, 로. al. Transplantation of adrenal medullard tissue to striatum in Parkinsonism: firs clinical trails. J Neurosurg 1985;62:169-73 $\mathrm{N}$ 
4 Madrazzo I, Drucker-Colin R, Diaz V. Martinez-Mata MDJ. Torres C. Becerril JJ. Open microsurgical autograft of adrenal medulla to the right caudate nucleus in two patients with intractable Parkinson's disease. N Engl J Med 1987:316:831-4.

5 Agid Y, Javoy-Agid F, Ruberg M. Biochemistry of neurotransmitters in Parkinson's disease. In: Marsden CD, Fahn S, eds Movement Disorders 2. London Butterworths, 1987:166-230.

6 Scherman D, Raisman R, Ploska A, Agid Y. 3H-Dihydrotetrabenazine, a new in-vitro monoaminergic probe in human brain. $J$ Neurochem 1988;50:1131-6.

7 Puymirat J, Javoy-Agid F, Gaspar P. Ploska A. Prochiantz A, Agid Y. Post-mortem stability and storage in the cold of brain enzymes. $J$ Neurochem 1979;32:449-54.

8 Fine A, Reynolds GP, Nakajima N, Jenner P. Marsden CD. Acute administration of 1methyl-4-phenyl-1,2,3,6-tetrahydropyridine affects the adrenal glands as well as the brain in the marmoset. Neurosci Lett 1985:58 123-6.

9 Riederer P, Rausch W-D, Birkmayer W, Jellinger K, Seeman D. CNS modulation of adrenal tyrosine hydroxylase in Parkinson's disease and metabolic encephalopathies. J Neural Trans 1978;Suppl. 14:121-31.

10 Den Hartog Jager WA. Histochemistry of adrenal bodies in Parkinson's disease. Arch Neurol 1970;23:528-33.

11 Olson L, Backlund E-O, Gerhardt G, Hoffer B. Lindvall O, Rose G, Seiger A, Strömberg I Nigral and adrenal grafts in Parkinsonism Recent basic and clinical studies. In: Yahr MD, Bergamnn KJ, eds. Advances in Neurology 1986; New York: Raven Press 85-95.

Accepted 26 April 1988

\section{Appendix}

Carmichael et al (New' Engl J Med, 1988, 254) have recently reported a significant decrease in noradrenaline, adrenaline and dopamine concentrations in adrenal medullas of three patients with Parkinson's disease compared with 15 controls. The discrepancies between their results and the present data may be due to differences in age and/or preterminal conditions between the subjects examined in the two investigations.

\section{Delayed somatosensory evoked potentials in pernicious anaemia with intact peripheral nerves}

Sir: Vitamin B12 deficiency is known to affect the spinal cord, brain, optic nerves and peripheral nerves. ${ }^{1}$ However, it is not clear which part of the neuraxis is most sensitive. Several authors state that the peripheral nerves are usually abnormal by the time spinal cord disease is apparent. ${ }^{23}$ However, Victor ${ }^{4}$ stated that the spinal cord initially is affected. A detailed neuropathological study of 41 patients with pernicious anaemia ${ }^{1}$ suggested that the peripheral nerves are rarely involved in early disease and that the earliest neuropathological evidence of Vitamin B12 deficiency is ballooning of large axons in the dorsal columns of the low cervical cord (spongiform change). At this stage a thin rim of myelin could be seen around the ballooned axons though there soon followed evidence of demyelination.

Neurophysiological evidence, however, has shown that sub-clinical peripheral nerve involvement is common in patients with Vitamin B12 deficiency. Gilliatt et $a l^{5}$ showed that antidromic lateral popliteal nerve action potentials were reduced at the knee in three out of four patients with pernicious anaemia and Cox-Klazinga and Endt $^{6}$ showed that distal conduction velocities to extensor digitorum brevis were reduced in 13 out of 20 such patients. Shorvon et $\mathrm{l}^{3}$ stated that of 50 patients with pernicious anaemia, the eight who had signs or symptoms of spinal cord disease all had abnormal peripheral nerves on electrophysiologic testing. Fine and Hallett $^{7}$ reported the details of peripheral and central nerve conduction in two elderly (age range 73-77 years) and one younger schizophrenic patient with pernicious anaemia; all were seen within 4 months of the onset of their symptoms. The two elderly patients had absent sural nerve action potentials but they were relatively normal in the third. The somatosensory evoked potentials (SSEPs) were delayed in all three patients (N20 latencies, 22-23 ms) and despite poor sural nerve sensory action potentials, two of the cases had normal Erb's point potentials (N9 latencies, 10-11 ms). They argued that the dorsal columns of the spinal cord were more sensitive to Vitamin B12 deficiency than the peripheral nerves. We present the case of a 72 year old spinster with pernicious anaemia whose neurological symptoms came on rapidly. Electrophysiological testing showed normal peripheral nerve conduction but delayed SSEPs. Some improvement was seen after 9 months' Vitamin B12 therapy.

She presented with a 2 month history of breathlessness and was found to have an abdominal mass and to be anaemic. At laparotomy under halothane/nitrous oxide anaesthesia a leiomyoma of the uterus was removed. Before operation she had a haemoglobin of $7.5 \mathrm{~g} / \mathrm{dl}$ with an MCV of $125 \mathrm{fl}$, oval macrocytosis and hypersegmented neutrophils. On discharge 3 weeks later she lacked motivation and was unsteady on her feet. Over the course of the next few weeks her unsteadiness increased. She woke one morning 8 weeks after the operation and noticed a tingling/numb sensation, as of sand-paper, in the tips of all the fingers of both hands. This spread to involve the palms over the next few days and was accompanied by waves of tingling spreading up her legs from her feet. Over the course of the ensuing fortnight her hands gradually became weaker, increasingly clumsy and she started to drop things. She was readmitted and examination revealed mild pallor, no glossitis, normal visual acuity, normal optic discs and normal eye movements. She was unable to stand unaided and had finger-nose and heel-shin ataxia. There was a downward drift of the outstretched left arm and athetoid movements of the fingers of both hands. Voluntary effort was ill-sustained and tone was flaccid. The knee jerks were pathologically increased while tendon reflexes in the arms and at the ankles were present and showed pathological spread. The plantar responses were flexor. Joint position sense was absent at the elbows and ankles but was preserved for gross movements at the knees. Pin-prick sensation was decreased in a glove and stocking distribution. Her haemoglobin was $12.4 \mathrm{~g} / \mathrm{dl}, \mathrm{MCV} 112 \mathrm{fl}$ and the serume Vitamin B12 $33 \mathrm{ng} / \mathrm{l}$ with normal whole blood and red cell folate levels. She hado intrinsic factor antibody and there was inad-O equate uptake of orally administered Vitamin B12 during a Schilling test. She was treated with parenteral Vitamin B12 and made a partial recovery over the course of 9 months. During her 2 month stay in hospital she became less lethargic and her dysaesthesiae subsided. Hand function remained impaired and she needed feeding until just prior to discharge. At 4 months she could walk unaided but still required large handled eating utensils. At 9 months she could walk quite well, could manage large buttons and could use normal eating utensils; it was still necessary, however, to cut up her food.

Electrophysiological assessment was performed 6 weeks after the onset of symptoms and after 9 months' treatment. Peripheral nerve action potentials were normal before and did not change after treatment. Supramaximal square wave pulses of $0.2 \mathrm{~ms}$ were delivered to the sural nerves (lower-calf), and the median and ulnar nerves (at the wrist) by a Medelec Mystro MS 20. Action potentials were recorded with skin temperatures in the range $30-32^{\circ} \mathrm{C}$ using surface electrodes over the respective nerves at the ankle and at the elbow. Pretreatment sural 